\title{
Perceived Value Of Educational Hypermedia: An Exploratory Study
}

Yuan Gao, Ramapo College of New Jersey, USA

Xiaoyu Wu, Ramapo College of New Jersey, USA

\begin{abstract}
This paper explores the idea of perceived value of educational hypermedia by extending prior research in advertising and information systems. It proposes that the value of a course support site comes from both its information content and users' experience when they visit the site. The cognitive antecedents of a site's perceived value include perceived informativeness, perceived entertainment and perceived irritation. Through a field study using a course companion site and the subsequent data analysis via structural equation modeling (SEM), this study confirms that learners appreciate informative content in an entertaining format in accessing Internet-based course support. Findings of this study will help researchers and educators better understand the cognitive dimensions that enhance the perceived value of a learning technology.
\end{abstract}

Keywords: educational hypermedia, perceived value, course companion site

\section{INTRODUCTION}

$\mathscr{T}$ any studies have explored the effectiveness of technology-supported learning. Past research has shown inconsistent results on the determining factors of an effective Web-based learning system (Psaromiligkos \& Retalis, 2003). About half of the studies in the recent literature find Internetsupported learning more effective than its traditional counterpart, while the other half identifies no significant difference (Bekele \& Menchaca, 2008). For example, Bartini (2008) reports that students in a Web-enhanced section performed significantly better on exams than those in the traditional section. Conversely, Koeber (2005) finds no statistically significant difference between groups using or not using a course-supporting website, though students in the Web-enhanced section seem to perceive the course more favourably.

In technology-enhanced learning, it is the interaction between technology and the participants, i.e., students and instructors, that impacts student learning processes and subsequent learning outcomes (Wan, Fang, \& Neufeld, 2007). Existing literature in technology-mediated learning has largely focused on learning outcomes that can be observed and measured, i.e., actions and performance (such as grades), while ignoring the mediating role played by student learning processes (Bekele \& Menchaca, 2008). In particular, a learner's psychological processes refer to his or her cognitive and information processing activities, interests, motivation, and cognitive structures (Alavi \& Leidner, 2001). Very few studies have explored this dimension in technology-mediated learning (Benbunan-Fich \& Hiltz, 2003; Stafford, 2005; Wan et al., 2007).

Applying existing theories in adjacent reference disciplines to educational media contributes to theory building in technology-mediated learning (Hrastinski \& Keller, 2007). This paper reviews the research literature in advertising and information systems regarding consumer perceptions, attitude, and behavioural intentions in both the traditional media environment and the Web environment. It extends the existing research by examining educational media including Web-based course supporting products. One such product is the Web-based course companion that often accompanies textbooks. Authors and publishers are increasingly aware of the benefits of using this hypermedia for promoting educational products and competing for customers. Such online companion sites often provide students with contents that will potentially enhance students' learning effectiveness, such as chapter summaries, lecture slides, practice tests, and links to related cases, etc. Instructors may take into consideration the perceived value of the course companion site in deciding textbook adoptions. 
This study examines the factors that influence the perceived value of educational hypermedia from a learner's perspective. It reports findings of an exploratory study examining the relationships among a learner's cognitive antecedents, his or her assessment of the value of a course companion site, and the subsequent intention to use the site.

\section{PERCEIVED VALUE}

Generally, perceived value potentially comes from an object such as an advertising message, but may also come from the experience accompanying the exchange relationship between an individual and the object (Houston $\&$ Gassenheimer, 1987). The original models by Ducoffe on the perceived value of advertising in the traditional media (1995) and the perceived value of Web advertising (1996) serve as the foundation of the value concept in this study. Research related to the cognitive influences on attitude toward a website provides additional support for the theoretical constructs (Chen \& Wells, 1999).

Three perceptual antecedents influence online consumers' perceived value of a website and their intention to return. These perceptions include perceived informativeness, perceived entertainment, and perceived irritation. Gao and Koufaris (2006) find that perceived informativeness and perceived entertainment have significantly positive influence on both consumer attitude toward a website and the subsequent intention to return, while perceived irritation has a negative effect. Ducoffe (1996) finds that perceived informativeness, perceived entertainment and perceived irritation are consistent measurement criteria for assessing the overall value of Web advertising. In this study, we extend the roles of these perceptual antecedents to educational websites.

\section{PERCEIVED INFORMATIVENESS}

A website is considered informative if it is able to "inform consumers of product alternatives so that purchases yielding the greatest possible satisfaction can be made" (Ducoffe, 1996, p.22). The Chicago-school economists view informativeness of communication as a facilitator of efficient comparison shopping (Bloom \& Krips, 1982). Consumers consider information a major benefit of engaging in an exchange relationship (Bartos \& Dunn, 1974). Information is also one of the need-satisfying functions in media-related communications, according to the extended theory of uses and gratifications (McQuail, 1983). Chen and Wells (1999) find a significant positive correlation between perceived informativeness and attitude toward a website.

Providing information is the major function of a course companion site. In the exchange relationship of a learner engaging in using a course website, the learner expects the benefit of gaining course-related information to improve his or her learning effectiveness and course performance. For the site to be informative, it must contain relevant information that students find meaningful and useful. Aaker and Norris (1982) provide a broad-based definition for informative communication as "one that contains information that is truthful, complete, intelligible, relevant, unknown, and substantial enough to warrant processing" (p. 65). We here, accordingly, define an informative course companion site as one that provides truthful, relevant, and intelligible information that is unknown to a student or user. We hypothesize that an informative site will be perceived valuable and useful by the learner.

H1: Perceived informativeness is positively associated with perceived value of the site.

\section{PERCEIVED ENTERTAINMENT}

While content information delivers the worth of the website itself, the experience associated with the exchange relationship, i.e., users visiting the site, can be an important source of value as well (Houston \& Gassenheimer, 1987; Ducoffe, 1996). The Web is a major source of entertainment for the general public. Uses and gratifications research refers the entertainment value of a commercial exchange to its ability to fulfill audience needs for escapism, diversion, aesthetic enjoyment, or emotional release (McQuail, 1983). Koufaris, Kambil and Labarbera (2001) find a visitor's intrinsic enjoyment significantly influences his or her intention to return. The entertainment provided through a website's vividness and interactivity leads to a positive attitude and return intention (Coyle \& Thorson, 2001). Overall, an entertaining or likable website enhances visitor experience and thus increases the perceived value of the site. 
Examples of entertainment provided by course companion sites include online practice tests that come in the form of the (Who wants to be a) Millionaire TV show. Some companion sites use the Wheel of Fortune game format to help students reinforce their learning of key terms in each chapter. Students who perceive these forms of learning exercises entertaining are likely to consider the course website valuable to his or her learning effectiveness. In prior research, perceived entertainment is significantly and positively associated with perceived value of Web advertising and attitude toward a website (Ducoffe, 1996; Chen \& Wells, 1997; Gao \& Koufaris, 2006). We believe entertainment is an important source of value to a learner in the context of a course companion site and thus so hypothesize.

H2: Perceived entertainment is positively associated with perceived value of the site.

\section{PERCEIVED IRRITATION}

Visitor feelings of frustration and irritation are negative outcomes that often accompany Web surfing. Sometimes these are due to overly manipulative techniques. Research in traditional advertising has identified irritation as a significant factor that negatively impacts consumer attitude (Greyser, 1973). Ducoffe (1996) finds a significant and negative correlation between irritation and the value of Web advertising. Promotional techniques such as popup ads and animated banners annoy visitors and induce irritation (Gao, Koufaris, \& Ducoffe, 2004). On the other hand, visitors hold a generally positive view toward an organized website that minimizes irritation (Chen \& Wells, 1997). In traditional advertising research, perceived irritation causes a reduction in the effectiveness of a communications message and thus decreases the perceived value of the ad (Aaker \& Bruzzone, 1985). We believe a similar effect holds for a course website.

In a course companion site, some elements that induce irritation may not be intentional. For example, a companion site uses flash cards for students to use as a study guide. While these flash cards incorporate some interesting elements, they require that the client machine is Java enabled. Therefore a student trying to access that feature could end up with a dead link and has to either give up the flash cards feature or figure out how to enable the Java option of the browser. Similar to the case of commercial websites, visitor frustration or irritation arising from such encounters diminishes the perceived value of a course companion site and thus we so hypothesize.

H3: Perceived irritation is negatively associated with perceived value of the site.

\section{THE RESEARCH FRAMEWORK}

We believe that students who perceive a course website high in value tend to hold a generally favorable attitude toward the site, which in turn impacts his or her behavioral intentions, according to the theory of reasoned actions (TRA) (Ajzen \& Fishbein, 1980). The technology acceptance model (TAM) posits that perceived usefulness of technology predicts one's intention to use technology (Davis, 1989). We view perceived value of the course companion site in a similar vein to the construct of perceived usefulness of technology in TAM. We treat an online companion site as a form of a computer-based technology system, and hypothesize that perceived value of such a system, i.e. a course website, positively impacts intention to use.

H4: Perceived value of the site is positively associated with intention to use.

Figure 1 outlines the research propositions of the study. In this model, the three independent variables reflect a learner's cognitive and information processing activities, interest, and motivation in the learning process. In e-commerce and m-commerce research, perceived value is considered a major element in measuring customer satisfaction (Choi, Seol, Lee, Cho, \& Park, 2008). In technology-mediated learning, a learner's satisfaction with using technology attests to the affective dimension of learning outcomes (Wan et al., 2007). Henceforth, the dependent variables in this model are those non-observable and non-measurable affective outcomes that reflect a learner's appreciation of and satisfaction with the technology-mediated interface that facilitates learning. 


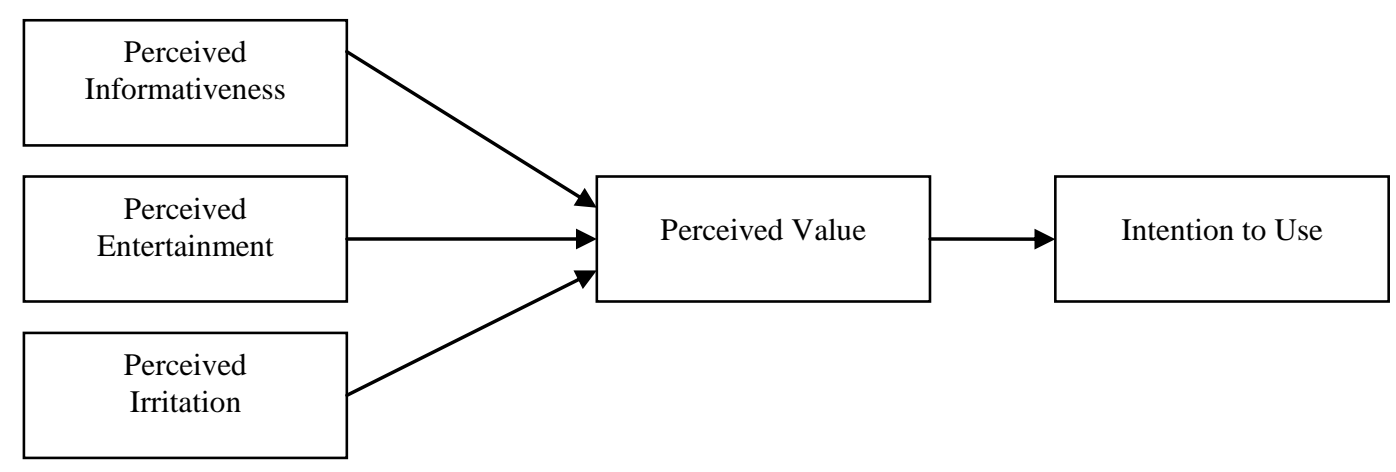

Figure 1: Perceived Value of a Course Companion Site

\section{METHODOLOGY}

An exploratory field study was conducted at a northeast college in the US to evaluate the hypotheses in the model above. A companion site of a textbook for an elective course in information systems was chosen and participants were drawn among students who were in the last three weeks of completing the prerequisite to that course. Thus the content of the course website should not be difficult for them to understand. The site contains chapter study guide, practice tests in both static and interactive formats, online games that reinforce concepts and terminologies, crossword puzzles involving related terms and concepts, and a list of hyperlinks to external resources for each chapter.

Participants were asked to help the instructor evaluate a course companion site for a potential choice of textbook for future use. The survey was conducted during the last twenty minutes of a number of classes held in a lab where each student has access to a computer. Participation was voluntary and students were assured that the survey was anonymous and they may choose to opt out of this task by leaving the survey blank.

Participants were directed to the course companion site and instructed to explore the site for about 10 minutes. They were also asked to explore one or two chapters in detail. Then, each participant was instructed to fill out a single-page questionnaire, which took less than an additional 5 minutes for the majority of the students. At the end of the 15-minute session, students were instructed to pass their completed surveys face-down, including blank ones, to the center isle and then forward them to the instructor, thus preserving anonymity of individual responses.

On the questionnaire, we use the three-item scales for each of the cognitive antecedents including perceived informativeness, perceived entertainment, and perceived irritation from Ducoffe (1995), changing the subject from advertising to websites. The only modification is that we replaced an item that says advertising "insults people's intelligence" with the website being "frustrating" as one of the items measuring perceived irritation. We believe this change is appropriate when taking into consideration how a course website differs from advertising.

For the dependent variables, we retain the website (advertising in the original case) being "valuable" and "useful" from Ducoffe (1996) to measure perceived value. To assess intention to use the course website, we developed a two-item scale that says I intend to "visit this site often" and "use this site frequently" when taking the course. This is consistent with earlier research in measuring behavioural intentions relating to specific outcomes as opposed to a general monolithic behaviour. For example, Gefen, Karahanna and Straub (2003) use a two-item measure for intended behaviour of shopping online, with one item on willingness to provide the e-vendor information to receive good service and another on willingness to provide credit card information for purchases. All items are on a 7-point differential scale ranging from "strongly disagree" to "strongly agree."

\section{MODEL FITTING}

We collected 112 usable surveys for data analysis. The participants were all undergraduate students and were about equally distributed in both genders. About $66 \%$ of the participants indicated that they have not used a 
course companion site in previous courses. We find no significant correlation between prior use of a course website and perceived value $(\mathrm{p}>.10)$ and thus drop prior use from further analysis.

We follow a generally recommended two-step process in applying structural equation modelling (SEM) (Anderson \& Gerbing, 1987). First, we assess the convergent and discriminant validity of the measurement model through a confirmatory factor analysis (CFA) using AMOS 17.0. The measurement model in the CFA is revised by dropping two items that share a high degree of residual variance with other items, as we follow the standard methodology in scale development (Churchill, 1979; Gerbing \& Anderson, 1988), in a process similar to that reported in Gefen et al. (2003).

We also carefully examine the dropped items from a theoretical perspective. The first item dropped is "the website is pleasing," which is one of the three items measuring perceived entertainment. From a cognitive perspective, the adjective "pleasing" seems to tap into a slightly different affective dimension from what the other two items "entertaining" and "fun" tend to measure. We suspect this item might not be as pertinent to websites as to advertising, and we believe the resulting two items more coherently measure the latent variable of a website being entertaining. When comparing Cronbach's alpha values of the three-item scale to the one with the remaining two items only, we find dropping the "pleasing" item improves Cronbach's alpha from 0.784 to 0.916.

The second item dropped says the "course website provides timely information." In traditional media advertising, audiences and consumers might consider advertising an important source of timely and up-to-date product offerings. Timely information is thus an important aspect of informativeness of a commercial website. However, given the course website used in the field study, participants probably would have expected the site to remain unchanged for the duration of the course and thus would not consider it an important source of constantly updated information, even though they might perceive that it is "informative" or provides "relevant information" (the remaining two items measuring informativeness). Thus the timeliness item seems less pertinent to a course support site.

After dropping the two items, the measurement model shows acceptable fit. The likelihood ratio chi-square test shows that chi-square is not significant at .05 level in this case (Chi-square $=45.165, \mathrm{df}=34, \mathrm{p}=0.095$ ), indicating the model cannot be rejected. Chi-square per degree of freedom (CMIN/DF), i.e., the relative Chi-square, is 1.328 , satisfying the recommend $<2$ criterion for a good fit. Other indices of model fit including normed fit index (NFI), incremental fit index (IFI), Tucker-Lewis Index (TLI) and comparative fit index (CFI) all exceed the recommended threshold level of 0.9 ( $\mathrm{NFI}=0.945, \mathrm{IFI}=0.986$, TLI=0.972, $\mathrm{CFI}=0.985)$. The root mean square error of approximation (RMSEA) is .054, below the recommended <.08 level (Hu \& Bentler, 1999; Jarvenpaa, Tractinsky, \& Vitale, 2000).

Factor score weights from CFA output show that items belonging to the same scale load highest on their respective factors while items belonging to different scales load highest on different factors. In addition, all item indicators show significant relationships with their associated latent variables, providing evidence of convergent validity, and the correlations between latent variables are significantly lower than 1.0 (or -1.0) showing good discriminant validity (Bagozzi \& Phillips 1982).

We tested the reliability of all the scales using Cronbach's alpha (see Table 1). All five variables, including perceived informativeness and perceived entertainment as modified, exhibit high degrees of reliability with the Cronbach's alpha values exceeding the recommended 0.7 (Nunnally, 1978).

Table 1: Scale Reliability

\begin{tabular}{|l|c|}
\hline \multicolumn{1}{|c|}{ Scale } & Cronbach's Alpha \\
\hline Informativeness & 0.736 \\
\hline Entertainment & 0.916 \\
\hline Irritation & 0.810 \\
\hline Perceived Value & 0.853 \\
\hline Intention to Use & 0.919 \\
\hline
\end{tabular}




\section{HYPOTHESIS TESTING}

We then test our structural model in AMOS 17.0, using standardized maximum likelihood estimation. Chisquare is not significant at 0.01 but is at 0.05 level (Chi-square $=58.752, \mathrm{df}=37, \mathrm{p}=0.013$ ). Since this statistic is sensitive to sample size and is often significant even for models with good fit, we further examine alternative fit indices. CMIN/DF is 1.588, satisfying the recommend <2 criterion for a good fit (Hu \& Bentler, 1999) and RMSEA is 0.072 , below the recommended 0.08 threshold (Jarvenpaa et al., 2000). Other fit indices all exceed the recommended threshold level of 0.9 ( $\mathrm{NFI}=0.929$, IFI=0.972, TLI=0.949, CFI=.971). Thus we believe overall the structural model shows acceptable fit.

Correlations among the variables are illustrated in Fig. 2. The model explains $76.1 \%$ of the variance in perceived value, and $69.6 \%$ of the variance in intention to use.

Perceived informativeness and perceived value have a standardized coefficient of 0.820 ( $p<0.01$ ), indicating support for H1. Perceived entertainment and perceived value have a standardized coefficient of $0.198(\mathrm{p}<$ 0.01 ), indicating support for $\mathrm{H} 2$. However, perceived irritation and perceived value are not significantly correlated ( $>$ > 0.10), thus $\mathrm{H} 3$ is not supported in this study. Lastly, perceived value and intention to use have a standardized coefficient of 0.834 ( $\mathrm{p}<0.01$ ) indicating support for $\mathrm{H} 4$.

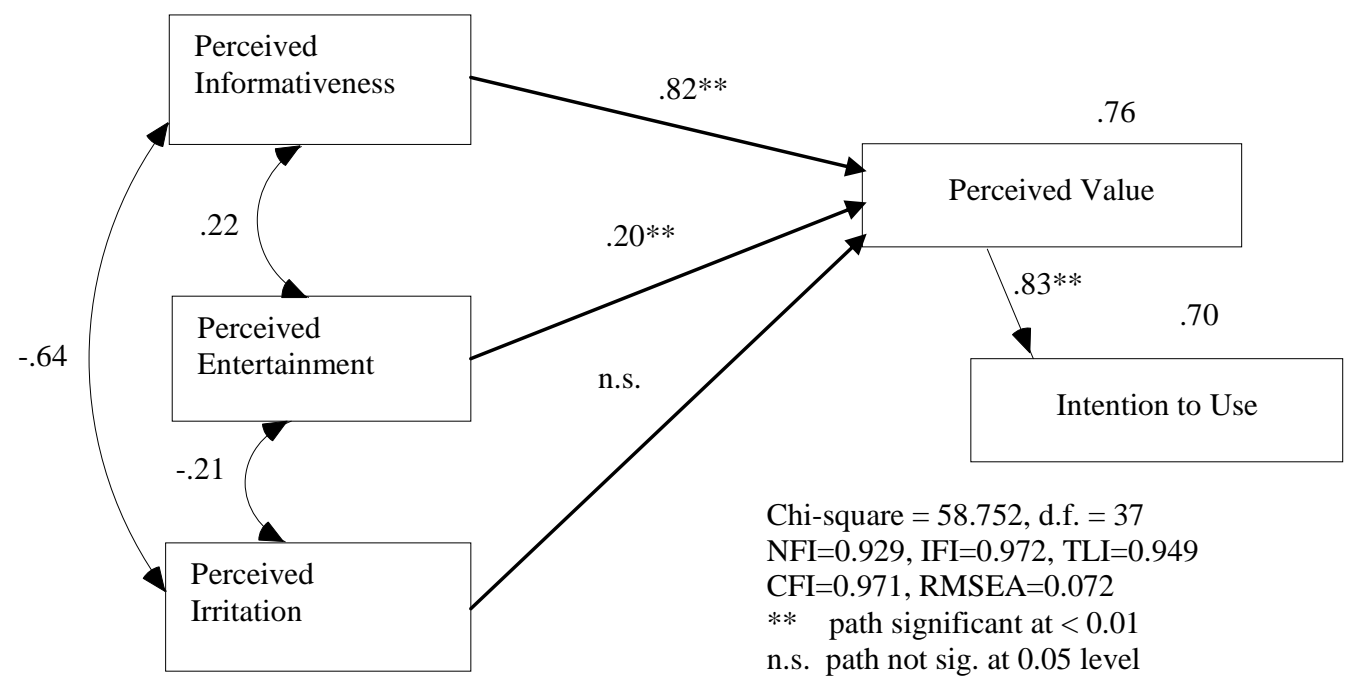

Figure 2: Structural Model Standardized Path Coefficients

\section{DISCUSSION}

Results from investigating the structural model indicate that information contained in a course website is the main source of perceived value. Perceived entertainment also contributes to the perceived value of the site. This study confirms the roles of perceived informativeness and perceived entertainment as important predictors of perceived value. The current research is based on a Web-based textbook companion but can be replicated with a website specifically developed by an instructor for a particular course. Results of this study also confirm an important relationship in the TAM model that perceived usefulness, i.e., value of technology, significantly influences a user's intention to use technology.

The hypothesis that perceived irritation reduces perceived value of the site is not supported in this study. One possible explanation for the insignificant relationship between perceived irritation and perceived value could be the absence of sales motivation in the case of course companion sites as opposed to the case of advertising. In both 
traditional advertising and Web advertising, consumers are passively fed with advertising by intrusive means of product promotion. For example, TV commercials interrupt programs in progress and Internet pop-up and banner ads annoy the Web users. In contrast, learners using course companion websites go actively seeking information on the site where the sales motivation is largely absent. Thus it is conceivable that perceived irritation might have less power in predicting the perceived value of an educational site. Another possible reason is that the site employed in this exploratory study happens to be minimally irritating.

\section{CONCLUSION}

This paper explores the notion of perceived value of educational hypermedia by extending prior research in perceived value of Web advertising. It confirms that learners accessing an Internet-based course companion are just like visitors to a commercial website in forming their perception of the site's value - informative content in a form as entertaining as possible.

Much of the existing research on technology-mediated learning has focused on the effect of technology on measurable and observable learning outcomes (Bekele \& Menchaca, 2008). This study explores the effect of the perceptual antecedents of a student's psychological learning processes on non-measurable results in the affective dimension. This approach complements existing research in shedding light beyond the simple causal effect of experimental studies in the adoption of educational technology. Future research should further investigate how learning technology affects a learner's cognitive structure and subsequent learning effectiveness. Findings of this study will help researchers and educators better understand the cognitive dimensions that enhance the perceived value of a learning technology. Accordingly, educators and practitioners in educational media can develop and employ such learning technology in a way that is perceived most favourably by students and users.

\section{AUTHOR INFORMATION}

Yuan Gao is an Associate Professor of IS at Ramapo College of New Jersey. He holds an MA in CIS from Brooklyn College, an MBA and a Ph.D. in Business from Baruch College-CUNY. His research interests include human computer interaction, online consumer behavior and educational hypermedia. He is the editor of a scholarly book Web Systems Design and Online Consumer Behavior, published by IGI Global. His research has appeared in DATA BASE for Advances in Information Systems, The Electronic Library, Journal of Electronic Commerce in Organizations, Journal of Applied Business Research, and Journal of Educational Multimedia and Hypermedia.

Xiaoyu Wu is an Assistant Professor of Economics at Ramapo College of New Jersey. She has a Ph.D. in Economics from the University of California, Riverside. Her research interests include productivity analysis, applied econometrics, environmental economics, and educational technology. Her research has appeared in Economics Bulletin, Journal of Applied Business Research, and a number of conference proceedings.

\section{REFERENCES}

1. Aaker, D.S., \& Bruzzone, D.E. (1985). Causes of irritation in advertising, Journal of Marketing, 49(2), $47-$ 57.

2. Aaker, D.S., \& Norris, D. (1982). Characteristics of TV commercials perceived as informative, Journal of Advertising Research, 22(2), 61-70.

3. Ajzen, I., \& Fishbein, M. (1980). Understanding Attitudes and Predicting Social Behavior. Englewood Cliffs, NJ: Prentice-Hall.

4. Alavi, M., \& Leidner, D.E. (2001). Research commentary: technology mediated learning - a call for greater depth and breadth of research, Information Systems Research, 12(1), 1-10.

5. Anderson, J.C., \& Gerbing, D.W. (1987). Structural equation modeling in practice: a review and recommended two step approach, Psychological Bulletin, 103, 411-423.

6. Bagozzi, R.P., \& Phillips, L.W. (1982). Representing and testing organizational theories, Administrative Science Quarterly 27, 459- 489.

7. Bartini, M. (2008). An empirical comparison of traditional and Web-enhanced classrooms, Journal of Instructional Psychology, 35(1), 3-11. 
8. $\quad$ Bekele, T.A., \& Menchaca, M.P. (2008). Research on Internet supported learning: a review, The Quarterly Review of Distance Education, 9(4), 373-405.

9. Bloom, P.N., \& Krips, J. (1982). An experiment in the economics of advertising, Journal of Marketing and Public Policy, 1, 25-42.

10. Benbunan-Fish, R., \& Hiltz, S.R. (2003). Mediators of the effectiveness of online courses, IEEE Transactions on Professional Communication, 46(4), 298-312.

11. Bartos, R., \& Dunn, T.F. (1974). The Consumer View of Advertising. New York: American Association of Advertising Agencies.

12. Chen, Q., \& Wells, W.D. (1999). Attitude toward the site, Journal of Advertising Research, 39(5), 27-38.

13. Choi, J., Seol, H., Lee, S., Cho, H., \& Park Y. (2008). Customer satisfaction factors of mobile commerce in Korea, Internet Research, 18(3), 313-335.1

14. Churchill, G.A.J. (1979). A paradigm for developing better measures of marketing constructs, Journal of Marketing Research, 16, 64-73.

15. Coyle, J.R., \& Thorson, E. (2001). The effects of progressive levels of interactivity and vividness in Web marketing sites, Journal of Advertising, 30(3), 65-77.

16. Davis, F.D. (1989). Perceived usefulness, perceived ease of use, and user acceptance of information technology, MIS Quarterly, 13, 319-340.

17. Ducoffe, R.H. (1995). How consumers assess the value of advertising, Journal of Current Issues and Research in Advertising, 17(1), 1-18.

18. Ducoffe, R.H. (1996). Advertising value and advertising on the Web, Journal of Advertising Research, 36(5), 21-34.

19. Gao, Y., \& Koufaris, M. (2006). Perceptual antecedents of user attitude in electronic commerce, Database for Advances in Information Systems, 37(2-3), 42-50.

20. Gao, Y., Koufaris, M., \& Ducoffe, R. (2004). An experimental study of the effects of promotional techniques in Web-based commerce, Journal of Electronic Commerce in Organizations, 2(3), 1-20.

21. Gefen, D., Karahanna, E., \& Straub, D.W. (2003). Trust and TAM in online shopping: an integrated model, MIS Quarterly, 27(1), 51-90.

22. Gerbing, D.W., \& Anderson, J.C. (1988). An updated paradigm for scale development incorporating unidimensionality and its assessment, Journal of Marketing Research, 25, 186-192.

23. Houston, F.S., \& Gassenheimer, J.B. (1978). Marketing and exchange, Journal of Marketing, 51(4), 3-18.

24. Hrastinski, S., \& Keller, C. (2007). Computer-mediated communication in education: a review of recent research, Educational Media International, 44(1), 61-77.

25. Hu, L.T., \& Bentler, P.M. (1999). Cutoff criteria for fit indexes in covariance structure analysis: conventional criteria versus new alternatives, Structural Equation Modeling, 6(1), 1-55.

26. Jarvenpaa, S.L., Tractinsky, N., \& Vitale, M. (2000). Consumer trust in an Internet store, Information Technology and Management, 1, 45-71.

27. Koeber, C. (2005). Introducing multimedia presentations and a course website to an introductory sociology course: how technology affects student perceptions of teaching effectiveness, Teaching Sociology, 33(3), 285-300.

28. Koufaris, M., Kambil, M.A., \& Labarbera, P.A. (2001). Consumer behavior in Web-based commerce: An empirical study. International Journal of Electronic Commerce, 6(2), 131-154.

29. McQuail, D. (1983). Mass Communication Theory: An Introduction. London: Sage Publications.

30. Nunnally, J.C. (1978). Psychometric Theory. New York: McGraw Hill.

31. Pedhazur, E.J., \& Schmelkin, L.P. (1991). Measurement, Design, and Analysis: An Integrated Approach. Hillsdale, NJ: Lawrence Erlbaum Associates.

32. Psaromiligkos, Y., \& Retalis, S. (2003). Re-evaluating the effectiveness of a Web-based learning system: a comparative case study, Journal of Educational Multimedia and Hypermedia, 12(1), 5-20.

33. Stafford, T.F. (2005). Understanding motivations for Internet use in distance education, IEEE Transactions on Education, 48(2), 301-306.

34. Wan, Z., Fang, Y., \& Neufeld, D.J. (2007). The role of information technology in technology-mediated learning: a review of the past for the future, Journal of Information Systems Education, 18(2), 183-192. 